\title{
Investigating past eruptive activity of a silicic shallow submarine volcano using FTIR volatile analyses
}

\author{
I.M. MCINTOSH ${ }^{1}$, K. TANI ${ }^{2}$, A.R.L. NICHOLS ${ }^{3}$, Q. \\ CHANG $^{1}$, AND J.-I. KIMURA ${ }^{1}$ \\ ${ }^{1}$ JAMSTEC, 2-15 Natsushima, Yokosuka, Japan 237-0061 \\ ${ }^{2}$ National Museum of Nature and Science, Tsukuba, Japan \\ 305-0005 \\ ${ }^{3}$ University of Canterbury, Private Bag 4800, Christchurch \\ 8140, New Zealand
}

Eruptions of silicic magmas like rhyolite are controlled by the rate and extent of bubble growth that occurs when magmatic volatiles, chiefly $\mathrm{H}_{2} \mathrm{O}$ and $\mathrm{CO}_{2}$, exsolve into the vapour phase during magma ascent. When erupted magma cools quickly enough to form volcanic glass, the dissolved volatile contents of this glass form a geochemical record that can be used to interpret degassing and eruption processes. However, silicic volcanic glasses are vulnerable to secondary hydration (i.e. slow diffusive addition of outside water in the time since eruption), which overprints the eruptive volatile record. Silicic submarine eruption products are especially vulnerable to this hydration. Moreover, the relative lack of material suitable for radiocarbon dating makes it difficult to obtain ages for late Quaternary submarine eruptions. It is therefore challenging to reconstruct the past eruptive activity of silicic submarine volcanoes that may pose a future hazard.

Using new Fourier Transform Infrared spectroscopy (FTIR) methods for measuring water speciation (i.e. molecular $\mathrm{H}_{2} \mathrm{O}_{\mathrm{m}}$ and hydroxyl groups $\mathrm{OH}$ ) of vesicular and hydrated glasses, we demonstrate that this volatile record can illuminate past eruptions of submarine volcanoes. We present data for Oomurodashi, an active, shallow, silicic submarine volcano only $60 \mathrm{~km}$ from Tokyo Bay. Geochemistry confirms Oomurodashi is the source of a $\sim 11.5 \mathrm{ka}$ subaerial tephra deposit on nearby inhabited islands. We infer from pumice volatile contents and tephra characteristics that this deposit was formed by explosive submarine phreatomagmatic activity that produced the shallow central crater in the submarine edifice. Volatile contents of in situ submarine lavas are lower than expected for their current water depth and comparison with past sea level implies that these effusive eruptions occurred at $\sim 8-9$ and $\sim 12$ ka during times of lower sea level. Although all matrix glasses have experienced hydration, water speciation data suggest this is consistent with low temperature secondary hydration following eruption rather than hydration during cooling within a submarine plume. FTIR volatile analyses therefore have potential to be invaluable for future studies of silicic submarine volcanism. 